\title{
A Study on the Degradation of Mechanical Properties for the Carbon Composite at a High Temperature and High Humidity of Environment
}

\author{
Sun Ho Go ${ }^{1}$, Sung Woo Hong ${ }^{2}$, Hong Gun $\mathrm{Kim}^{3}$, Lee Ku Kwac ${ }^{4}$ \\ ${ }^{I}$ (Department of Mechanical Engineering, Jeonju University, South Korea) \\ ${ }^{2}$ (Module System R\&D Group, Institute of Automotive Convergence Technology, South Korea) \\ ${ }_{3}^{3}$ (Institute of Carbon Technology, Jeonju University, South Korea) \\ ${ }^{4}$ (Department of Manufacturing and Design Engineering, Jeonju University, South Korea)
}

\begin{abstract}
Carbon Fiber Reinforced Plastic(CFRP) materials of the aircraft can absorb water, which could decrease the adhesion strength of these materials and cause their volumes to change with variation in internal stress. Therefore, it is necessary to study the changes of the characteristics in the extreme environments in order to identify the environmental impact of CFRP. In this study, we evaluated the properties of CFRP by the tensile test and bending test as specified in ASTM standard. After the fabrication of the CFRP specimen directly by using a water bath to set the environmental temperature and humidity, specimens were soaked in distilled water at $75^{\circ} \mathrm{C}$, for one week, two weeks and three weeks respectively. Mechanical Characteristics of CFRP were observed through Tensile test and Bending test.
\end{abstract}

Keywords: high temperature, strength reduction, temperature chamber, tensile strength

\section{Introduction}

Carbon fiber can be used in the form of composite material such as carbon fiber reinforced high molecular polymer composite material, carbon fiber reinforced metallic composite material, carbon fiber reinforced ceramic composite material, and carbon fiber reinforced carbon composite material thanks to its excellent mechanical characteristics and lightness, driving out competing materials that have been used so far and expanding its application cases to chemical industry, sport goods, automotive industry, bio engineering as well as to aerospace area such as application for space shuttle[1,2].

The carbon fiber reinforced plastic, one of the many carbon-based composite materials that uses carbon fiber as its stiffening agent and thermo-hardening resin as base material, demonstrates an excellent mechanical property for static load but cannot be expected to demonstrate such excellent mechanical property in a high temperature and humid environment. The very mechanical property that makes the composite material such an excellent substance is known to be changing the molecular arrangement and chemical property of the base material when faced with some environment factors such as temperature and humidity, especially when infiltrated with moisture, thereby deteriorating the interfacial and mechanical property of the consisting materials. Furthermore, the moisture absorbed by the base material is known to be changing the inner stress condition by expanding absorbed moisture as well as deteriorating the bond stiffness by separating the chemical bond between fiber and base material. This study, therefore, is aimed at analyzing accurate tendency of such mechanical transformation by making a specimen using carbon fiber $3 \mathrm{~K}$ prepreg among various carbon fiber reinforced plastics and immersing it in a distilled water heated up to $75^{\circ} \mathrm{C}$ before performing a tension test and 3 -point bending test $[3,4]$.

\subsection{Laminating theory}

\section{Theoretical Background}

Majority of the theories on lamination consider that each laminated ply is stuck tightly with other ply and each ply is composed of uniform material with well-known physiological property. And the physiological property of each ply is Isotropic, Orthotropic, or Transversely Isotropic while each ply is in the state of plane stress. In the case of the laminated plate used in this study, its stress components can be applied as shown in equation (1) from the perspective of material mechanics.

$$
N_{a}=\sum_{i=1}^{n} t_{p l y}^{\left[\theta_{l}\right]} \sigma_{a_{l}\left[\theta_{l}\right]^{L}}
$$

Where $\mathrm{t}$ stands for the thickness of each ply, L laminate. And the extensional stiffness of the composite laminated plate should satisfy equation (2) below[5]. 


$$
A_{\alpha \beta}=\sum_{i=1}^{n} t_{p l y}^{\left[\theta_{l}\right]} Q_{\alpha \beta}^{\left[\theta_{l}\right]}
$$

\subsection{Molding process of carbon fiber pre-preg}

The carbon fiber prepreg is an aelotropic substance that demonstrates high stiffness, specific rigidity and excellent fatigue resistance but low shock resistance. There are diverse methods for molding carbon fiber prepreg including Press Molding Method, Vacuum Bag Molding Method and Autoclave Molding Method. The autoclave molding method applied to this study is used for manufacturing aerospace composite materials that do not require massive production volume but high stiffness, high strength and high quality property. They can be produced in uniform thickness with high temperature and vacuum pressure while the additional autoclave pressure helps improve the quality of surface profile. And its high bonding strength between layers improves fiber volumetric rate and eases elimination of bubbles between materials[6].

\subsection{Correlation of the composite material and the temperature, humidity}

Moisture would infiltrate into the base material owing to dispersion action when it contacts composite material or infiltrate into the interface owing to the capillary phenomenon. Such infiltration action is being accelerated if its surface is damaged and cracks from an exposure to elements and such infiltration prompts plasticizing action in which hydrogen-bond between molecules is broken owing to the moisture infiltration, which again lowers glass transition temperature thereby inflicting significant impact in decreasing its stiffness. The glass transition temperature drops by $20 \%$ per $1 \%$ absorption rate.

In general, composite materials thicker than certain level are known to take up to 10 years before the moisture penetrates down to the core of the lamination since its infiltration speed is very slow in the room temperature. However, it is absolutely necessary to identify what deteriorates the bonding property via the plasticization action which breaks down Van Del Waals bonding between high molecular polymer chains. In this paper, the author intends to highlight the need for such study by conducting the mechanical experiment[7].

\subsection{Manufacturing of specimen}

\section{Test Methods}

In this study, two specimens for $2.5 \mathrm{~T}$ tensile strength test and bending test were made through lamination of carbon fiber prepreg which is used as lightweight material, before their respective mechanical strength was assessed by performing tensile strength and 3-point bending test, respectively, on four different specimens that were prepared by immersing them in a hot water for zero week, 1 week, 2 weeks, and 3 weeks.

The carbon fiber $3 \mathrm{~K}$ prepreg used in the test was a fabric0type WSN-3K made by SK Chemical with its ingredients and mechanical property shown in Table 1 and Table 2, respectively.

First, a roughly $2.5 \mathrm{~T}$ (carbon fiber $3 \mathrm{~K}$, prepreg $15 \mathrm{Ply}$ ) specimen was produced by using the Ply lamination method with its melting temperature kept for $90 \mathrm{~m}$ at $85^{\circ} \mathrm{C}$, curing temperature for $90 \mathrm{~m}$ at $125^{\circ} \mathrm{C}$ and its vacuum pressure at -1 bar and autoclave pressure at 4 bar. The curing cycle applied for this specimen is shown in Fig. 1[8].

Table 1 Physical properties of carbon fiber 3K pre-preg

Physical Properties

\begin{tabular}{l}
\hline \hline - Prepreg Type : Woven Fabric \\
- Fiber Areal Weight : $240 \mathrm{~g} / \mathrm{m}^{2}$ \\
- Weave Style : Plain - Resin Content : $41 \%$ \\
- Thickness : $0.277 \mathrm{~mm}$ - Total Weight : $336 \mathrm{~g} / \mathrm{m}^{2}$
\end{tabular}

Table 2 Mechanical properties of carbon fiber $3 \mathrm{~K}$ pre-preg

\begin{tabular}{l} 
Mechanical Properties \\
\hline - Tensile Strength : $450 \mathrm{kgf} / \mathrm{mm}^{2}$ \\
- Tensile Modulus : $24 \times 10^{3} \mathrm{kgf} / \mathrm{mm}^{2}$ \\
- Fiber Density : $1.77 \mathrm{~g} / \mathrm{cm}^{2}$ \\
- Resin Density : $1.2 \mathrm{~g} / \mathrm{cm}^{2}$ \\
\hline
\end{tabular}




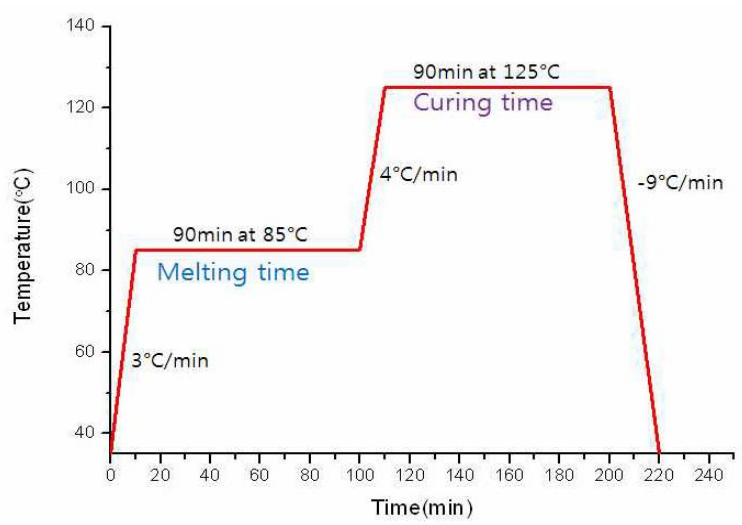

Figure. 1 Curing cycle of carbon fiber 3K prepreg

The specimen for tensile strength test was made in accordance with ASTM D-5083 with its mimetic diagram and test specimen processing as shown in Figure 2 performed, whereas the specimen for 3-point bending test was made in accordance with ASTM D-790 with its mimetic diagram and test specimen processing performed as shown in Fig.3[8-10].

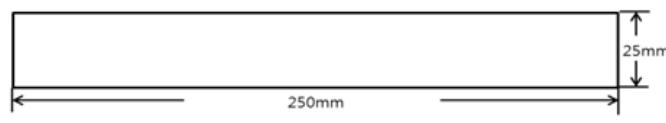

(a) Sketch of tensile test specimen

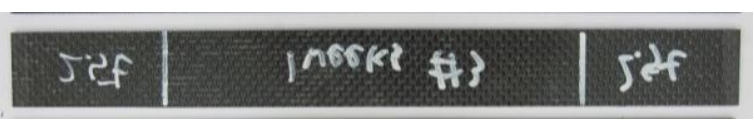

(b) Tensile test specimen

Figure. 2 Tensile specimen of carbon fiber $3 \mathrm{~K}$ prepreg

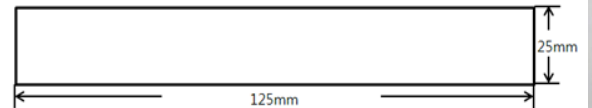

(a) Sketch of 3-point bending test specimen

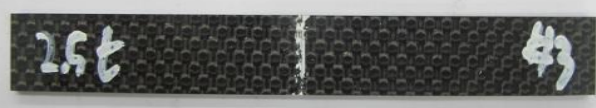

(b) 3-point bending test specimen

Figure. 3 3-Point bending specimen of carbon fiber $3 \mathrm{~K}$ prepreg

\subsection{High temperature and humidity conditions}

In an attempt to meet test conditions by using the prepared specimens, a thermal chamber was used to create a high temperature and moist environment. A total of four specimens, one that is given with no condition and three remaining specimen kept in a hot water for zero week, 1 week, 2 weeks and 3 weeks within 1 bar inside the thermal chamber (ambient temperature: $75^{\circ} \mathrm{C}$, relative humidity: $100 \%$ ) were created while their reliability against environmental conditions were sustained by checking temperature once per day using an infrared temperature sensor. The inside and outside condition of the thermal chamber with regard to this test are shown in Fig. 4 and Fig. 5.
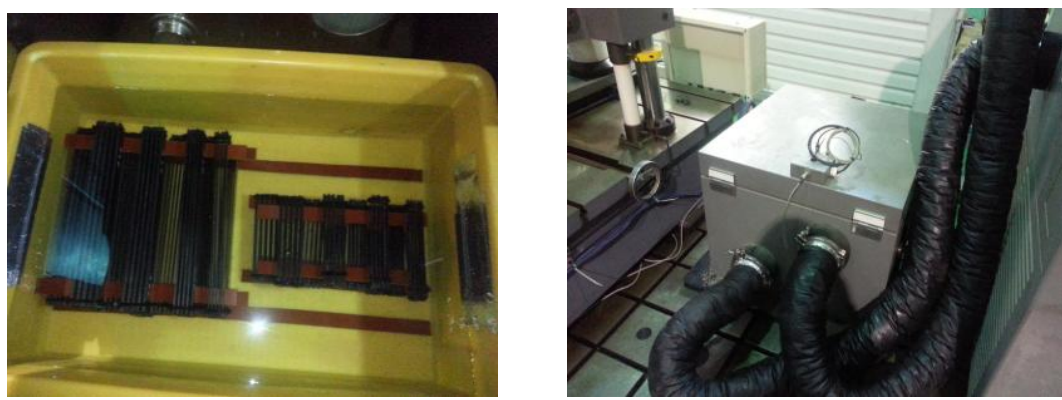

Figure. 4 Inside view of temperature chamber

Figure. 5 Set the environment of temperature and humidity

\subsection{Tensile testing}

The tensile strength test was performed to calculate the relationship between stress and elongation percentage by recording the strength and deformation required to break a standard specimen with specified size and shape by pulling it to one direction at continuous speed. And the 820 universal material property tester by MTS in the United States was used for the main specimen. The head speed was set at $2 \mathrm{~mm} / \mathrm{min}$ in accordance 
with ASTM D-5083 while its tensile strength was analyzed by using equation (3) and tensile strain rate by using equation (4).

$$
\sigma_{i}=P_{i} / A
$$

where :

$\sigma_{i}=$ tensile stress at $\mathrm{i}$ th data point, $\mathrm{MPa}$

$P_{i}=$ load at $\mathrm{i}$ th point, $\mathrm{N}$

$A=$ average cross-sectional area $\mathrm{mm}^{2}$

$$
\varepsilon_{i}=\delta_{i} / L_{g}
$$

where :

$\varepsilon_{i}=$ tensile strain at $\mathrm{i}$ th data point, $\mathrm{N}$

$\delta_{i}=$ extensometer displacement at $\mathrm{i}$ th data point, $\mathrm{mm}$

$L_{g}=$ extensometer gage length, $\mathrm{mm}$

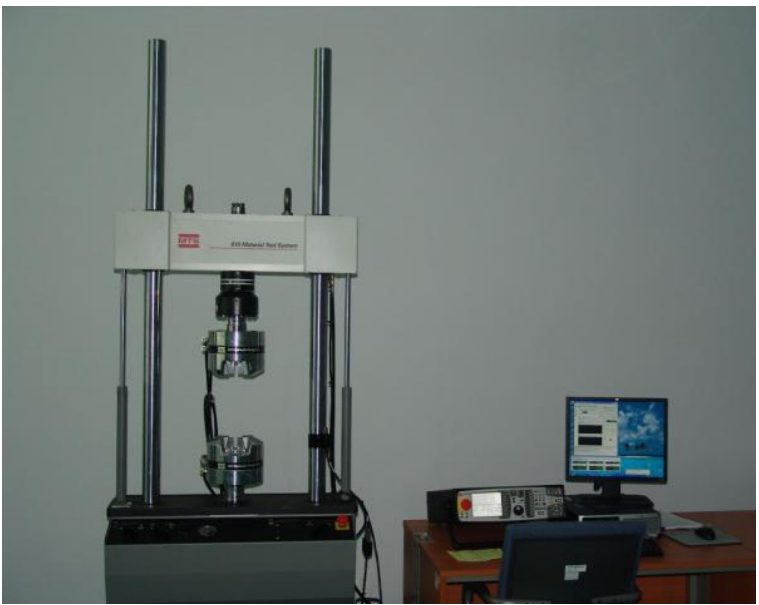

Figure. 6 Experiment system for tensile test

\subsection{3-point bending testing}

The 3-point bending test is performed to determine softness or strength of a specific material by measuring deformation resistance and breaking strength when a bending moment was exerted to the material. The 820 universal material tester by MTS in the United States was used for the test while the span distance and head speed were set up in accordance with the ASTM D-790 specifications and its bending strength and bending deformation rate analyzed using equation (5) and equation (6), respectively. The tensile strength test was performed by comparing its respective strength measurements according to the different period of being exposed to high temperature and moist condition while measurements of five different specimens were averaged to ensure the reliability of the test.

$$
\sigma=3 P L / 2 b d^{2}(5)
$$

where :

$\sigma=$ stress in the outer fibers at midpoint, $\mathrm{MPa}$

$P=$ lad at a given point on the load-deflection curve, $\mathrm{N}$

$L=$ support span, $\mathrm{mm}$

$b=$ width of beam tested, $\mathrm{mm}$

$d=$ depth of beam tested, $\mathrm{mm}$

where :

$$
\varepsilon=6 D d / L^{2}(6)
$$

$\varepsilon=$ strain in the outer surface, $\mathrm{mm} / \mathrm{mm}$

$D=$ maximum defection of the center of the beam, $\mathrm{mm}$

$L=$ support span, $\mathrm{mm}, \mathrm{d}=$ depth, $\mathrm{mm}$ 


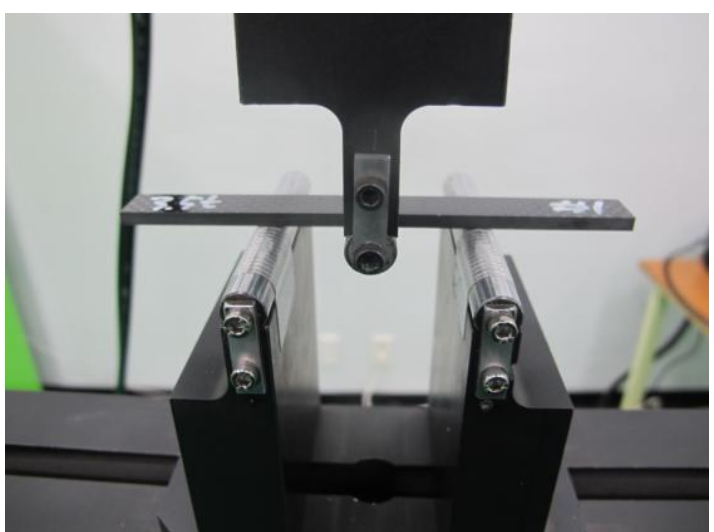

Figure. 7 Experiment system for bending test

\subsection{Tensile testing}

\section{Results And Discussion}

It was measured as 690MPa for normal specimen, 634MPa for the specimen kept for one week in a hot water, $609 \mathrm{MPa}$ for the specimen kept for two weeks, and $578 \mathrm{MPa}$ for the specimen kept for three weeks, or equivalent of strength reduction measuring $56 \mathrm{MPa}, 81 \mathrm{MPa}$ and $112 \mathrm{Mpa}$, respectively, as compared to the normal specimen. and the respective S-S Curve for different type is shown in Fig. 8 through Fig. 11 while related data shown in Table 3 and tendency in the strength deterioration in Fig. 12.

As such, deterioration in the tensile strength and stiffness of the specimens that were made of carbon composite material when they were exposed to a hot and humid environment was confirmed. In particular, the tensile strength of the specimen which was exposed for one week dropped rapidly and decreased over time but no linear pattern was observed in the specimen. This is believed to be stemming from the fact that carbon fiber and resin, both aelotropic materials, did not demonstrate constant pattern in their moist immersion rate depending on the extent of internal processing.

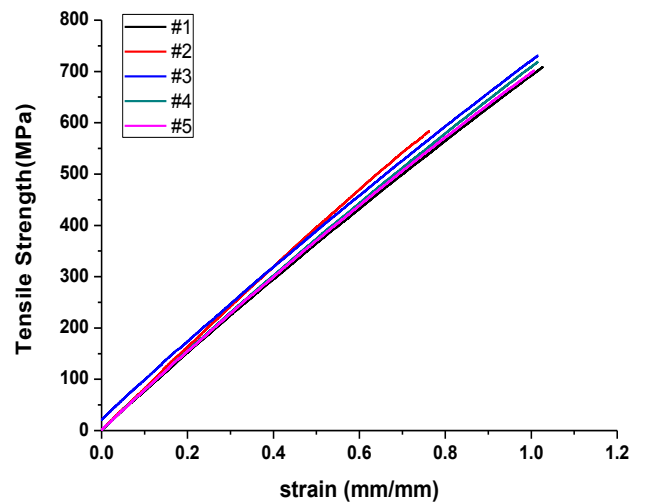

Figure. 8 Results obtained from tensile test(normal)

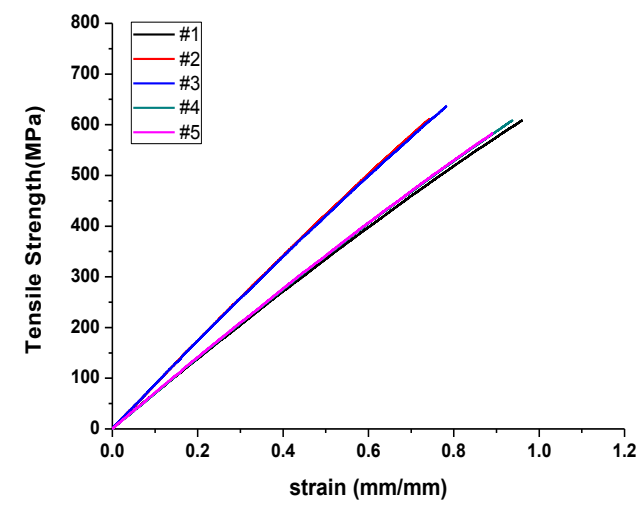

Figure. 10 Results obtained from tensile test (2weeks)

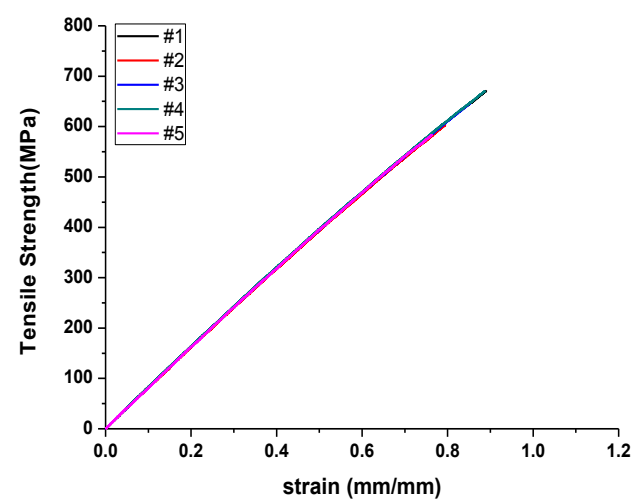

Figure. 9 Results obtained from tensile test(1week)

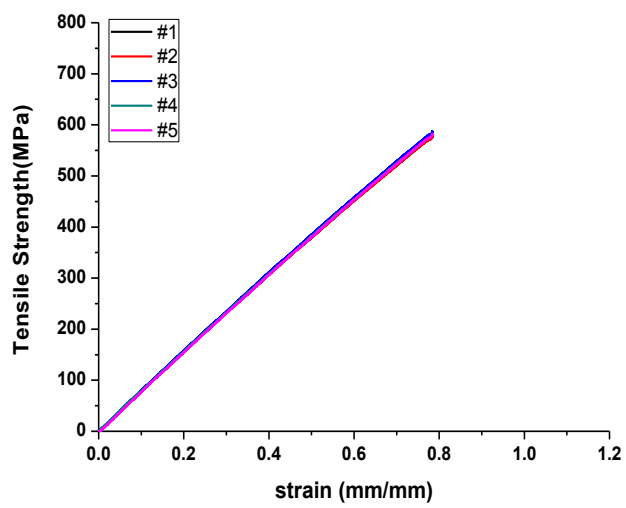

Figure. 11 Results obtained from tensile test (3weeks) 
Table 3 Data of tensile test(normal - 3weeks)

\begin{tabular}{|c|c|c|c|c|}
\hline $\begin{array}{c}\text { Specimen } \\
\text { No. }\end{array}$ & $\begin{array}{c}\text { Normal } \\
(\mathrm{MPa})\end{array}$ & $\begin{array}{c}1 \text { week } \\
(\mathrm{MPa})\end{array}$ & $\begin{array}{c}2 \text { weeks } \\
(\mathrm{MPa})\end{array}$ & $\begin{array}{c}3 \text { weeks } \\
(\mathrm{MPa})\end{array}$ \\
\hline 1 & 706.9 & 671.04 & 609.1 & 577.1 \\
\hline 2 & 583.9 & 603.25 & 612.4 & 579.1 \\
\hline 3 & 736.3 & 645.67 & 637.0 & 587.7 \\
\hline 4 & 723.9 & 670.04 & 608.3 & 563.9 \\
\hline 5 & 701.6 & 583.89 & 582.7 & 583.5 \\
\hline Average & 690.8 & 634.78 & 609.9 & 578.3 \\
\hline
\end{tabular}

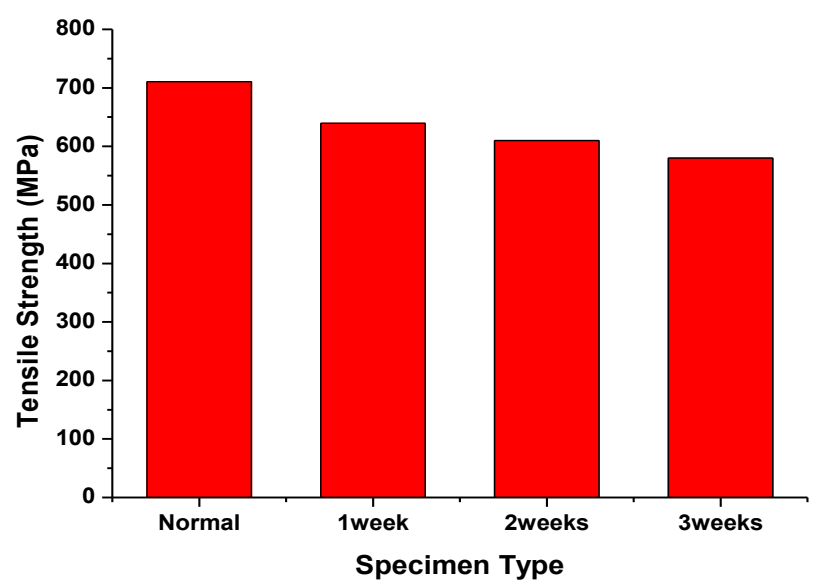

Figure. 12 Results obtained from tensile test(normal - 3weeks)

\subsection{Bending testing}

The bending test was performed by comparing their strength depending on the period being exposed to hot and humid condition while measurements of five different specimens were averaged to ensure the reliability of the test. It was measured as $291 \mathrm{MPa}$ for normal specimen, $286 \mathrm{MPa}$ for the specimen kept for one week in a hot water, 260MPa for the specimen kept for two weeks, and 248MPa for the specimen kept for three weeks, or equivalent of strength reduction measuring $5 \mathrm{MPa}, 31 \mathrm{MPa}$ and $43 \mathrm{Mpa}$, respectively, as compared to the normal specimen. and the respective S-S Curve for different type is shown in Fig. 13 through Fig. 16 while related data shown in Table 4 and tendency in the strength deterioration in Fig. 17.

As such, deterioration in the tensile strength and stiffness of the specimens that were made of carbon composite material when they were exposed to a hot and humid environment was confirmed. In particular, the stiffness of the specimen which was exposed for one week dropped least unlike in the case of its tensile strength but no linear pattern was observed in the specimen. This is believed to be stemming from the fact that the hydrogen bonding strength between molecules decreases owing to moist infiltration but its infiltration speed is very slow thereby maximizing the influence of temperature. Therefore, it is believed to be difficult to identify any clear trends in delamination between ply or in cracks in the base material given the characteristics of the aelotropic substance.

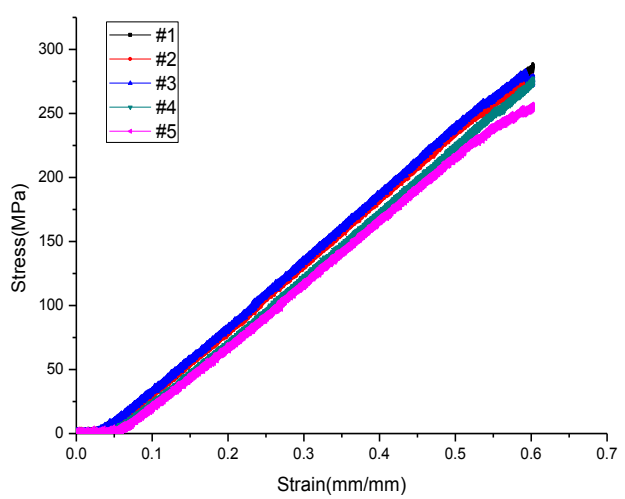

Figure. 13 Results obtained from bending test(normal)

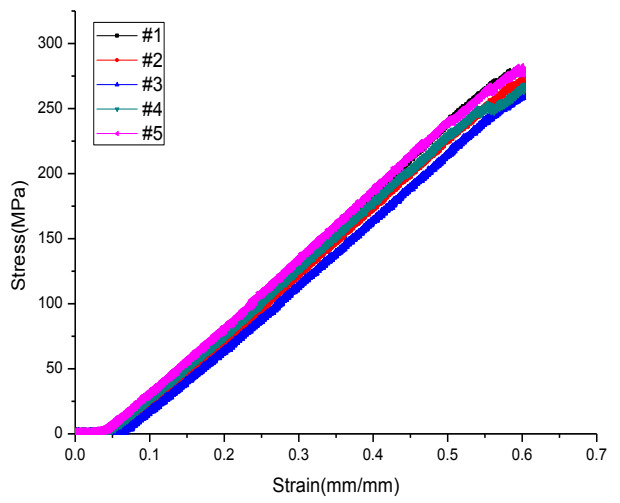

Figure. 14 Results obtained from bending test(normal) 


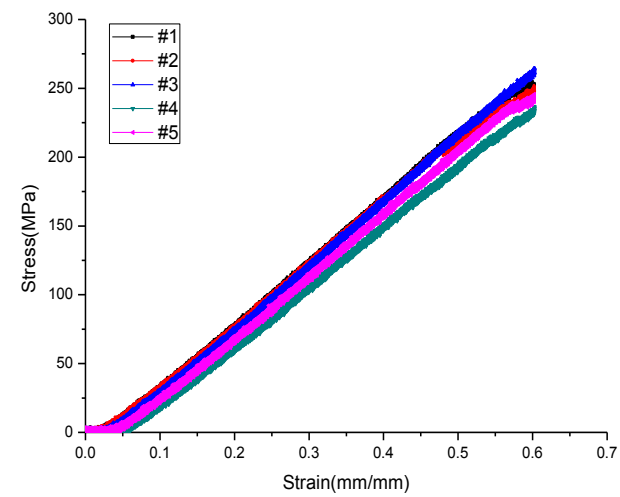

Figure. 15 Results obtained from bending test(normal)

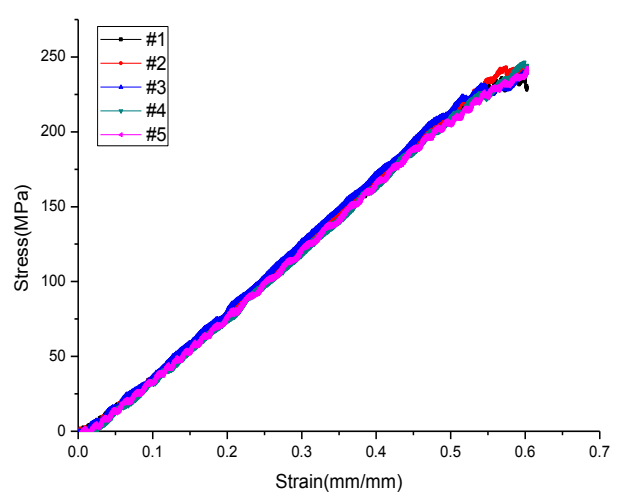

Figure. 16 Results obtained from bending test(normal)

Table 4 Data of bending test(normal - 3weeks)

\begin{tabular}{|c|c|c|c|c|}
\hline $\begin{array}{c}\text { Specimen } \\
\text { No. }\end{array}$ & $\begin{array}{c}\text { Normal } \\
(\mathrm{MPa})\end{array}$ & $\begin{array}{c}\text { 1week } \\
(\mathrm{MPa})\end{array}$ & $\begin{array}{c}2 \text { weeks } \\
(\mathrm{MPa})\end{array}$ & $\begin{array}{c}3 \text { weeks } \\
(\mathrm{MPa})\end{array}$ \\
\hline 1 & 291.9 & 281.8 & 254.6 & 243.1 \\
\hline 2 & 303.7 & 294.8 & 255.1 & 248.7 \\
\hline 3 & 286.2 & 282.3 & 268.5 & 255.1 \\
\hline 4 & 307.7 & 283.9 & 259.8 & 249.1 \\
\hline 5 & 268.9 & 287.1 & 262.4 & 245.9 \\
\hline Average & 291.6 & 286.0 & 260.1 & 248.3 \\
\hline
\end{tabular}

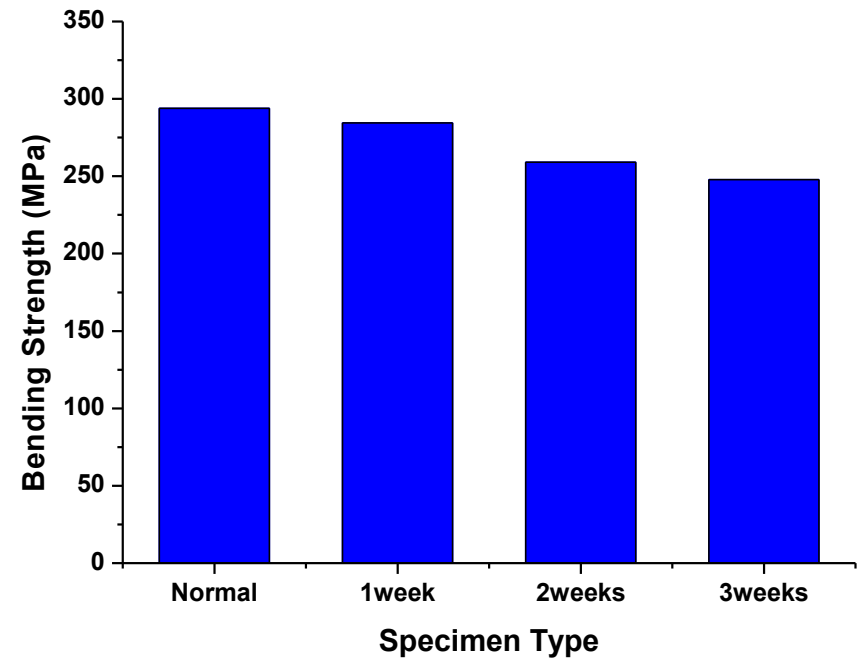

Fig. 17 Results obtained from bending test (normal - 3weeks)

\section{Conclusion}

In this paper, the tensile strength and bending strength tests were conducted on four different types of specimens before comparing the results with the related test conditions in an attempt to verify the correlation between the deterioration of mechanical strength of carbon fiber composite material and hot and humid condition. When the test conditions were sustained at $75^{\circ} \mathrm{C}$ for ambient temperature and $100 \%$ for relative humidity by using a thermal chamber, the strength has deteriorated continuously for three weeks, thereby confirming that a hot and humid condition exerts significant influence on the delamination between ply and crack development in the base material. but no linear result was observed with regard to the strength deterioration. Such result is believed to be stemming from the fact that infiltration into the interface is being realized with an irregular pattern due to the capillary reaction which was prompted by the air bubbles inside carbon fiber and resin which are both aelotropic substances. It is believed based on a preliminary research that the result is not so much influenced by moist infiltration as by hot temperature. 


\section{Acknowledgements}

This research was supported by basic science research program through the National Research Foundation of Korea(NRF) funded by the ministry of education, science and technology (No.2013R1A1A2061581) and financially supported by the National Foundation of Korea(NRF) funded by the Korea Government(MISP) (No.2014R1A2A1A11054594) and (No.2014R1A2A1A11053533)

\section{References}

[1] H. J. Shin, The Strength Evaluation and Nondestructive Testing of Carbon Fiber Composites, Jeonju University, Republic of Korea, MA, 2013.

[2] J. H. Kim, The Tensile Characteristic of Carbon and Silica Reinforced Composites Under Elevated Temperature, Journal of the Korean Society for Composite Materials, 16(3), 2003, 49-57.

[3] P. Cappa, K. McConnel and L. Zachary, A Temperature Calibration of a Temperature/Strain Transducer based on Two Strain Gauges, International Journal of the Strain, 29(4), 1993, 135-138.

[4] J. O. Lee, J. S. Lee and K. S. Cho, The Analysis of Failure Mechanism during Tensile of CFRP, Journal of the Korean Society for Composite Materials, 5(2), 1992, 11-23.

[5] S. K. Lee, S. K. Oh and K. W. Nam, A Study on the Fracture Behavior of CFRP in Tensile and Fracture Toughness Tests by Acoustic Emission, Journal of The Korea Society for Nondestructive Testing, 15(1), 1995, 277-290.

[6] M. G. Kim, S. K. Kang and C. G. Kim, Tensile Properties of CFRP Composites with Different Resin Composition under Cryogenic Temperature, Journal of The Korean Society for Composite Materials, 20(4), 2007, 1-8.

[7] Lee, S. E., Lee, W. J., Kim, C. G., "A Study on Tensile Properties of Multi-Walled Carbon Nanotube/Epoxy Composites", Journal of the Korean Society for Composite Materials, 17(5), 2004, 1-7.

[8] Standard Test Method for Tensile Properties of Reinforced Thermosetting Plastics using Straight-Slided Specimens, ASTM D 5083-02, 2002.

[9] Standard Test Method for Tensile Properties of Polymer Matrix Composite Materials, D3039/D3039M-14, 2014

[10] T. H. Kim, Analysis of Correlation according to the Orientation of Carbon Fiber Composite Mechanical and Thermal Properties, Jeonju University, Republic of Korea, MA, 2016. 